\title{
Rationalization of the Use of Alternative Rolling Stock for Transportation of Vegetable Cargo with Insufficient Number of Grain Hoppers
}

\author{
O. Lavrukhin ${ }^{1}$, V. Zapara ${ }^{1}$, H. Baulina ${ }^{1}$, Y. Zapara ${ }^{1}$, A. Kyman $^{2}$ \\ ${ }^{1}$ Department of manage freight and commercial work, Ukrainian State University of Railway Transport, Ukraine \\ ${ }^{2}$ Production Department "Directorate of Railway Transportation for Organization of Interaction of Ports and Port Stations" of the Ode- \\ sa Railway regional branch of Ukrzaliznytsya PJSC, Ukraine \\ *Corresponding authorE-mail: tilavalval@gmail.com
}

\begin{abstract}
The main problems of transportation of vegetable cargo by the Ukraine railway transport are considered. It was established that as grain export grows rapidly and subject to the current technical condition of the railway, the number of special rolling stock - grain hoppers - is insufficient. The article proposes using an alternative rolling stock - a covered car. The use of metal door panels in the car has been proposed to ensure the car loading without restrictions on the height of loading in the doorway space and the complete safety of the cargo with the increased use of the load capacity of covered cars. The influence of loading density of the loaded cargo on the degree of use of loading capacity and loading volume of the car was investigated when standard wooden door panels are used vs. proposed metal door panels. The study have proved significant economy of the covered car fleet during transportation of vegetable cargo with the use of metal door panels in the loading density range of the cargo from a minimum to $610 \mathrm{~kg} / \mathrm{m}^{3}$.
\end{abstract}

Keywords: Alternative rolling stock; economy of the covered car fleet; enclosure panel; loading density of the cargo; vegetable cargo.

\section{Introduction}

The development of the Ukrainian economy in the conditions of globalization essentially depends on the ability of its enterprises to jointly create competitive products on the global market. Grain is one of the strategic products offered today by the Ukrainian economy. The grain market is developing steadily, and therefore the need for grain transportation will grow. Grain industry is the basis and source of sustainable development of the national agricultural sector and the basis of Ukrainian agricultural exports. Over the past ten years, grain production in Ukraine has increased by $67 \%$ amounting to 62.2 MT in 2017.

Technical crops are an important component of grain crops in Ukraine (crops area is 9.1 to 9.3 million hectares, gross collection is about 20.0 MT), among which sunflower seeds stand apart (crop area of 6.2 million hectares, gross collection of 13.4 MT) According to the Ukroliyaprom Association, in the marketing year $2018 / 19$, production of 5.8 MT of sunflower oil is expected, including 5.4 MT for export (crop area 9.1 to 9.3 million hectares, gross collection of about $20.0 \mathrm{MT}$ ).

The transportation of grain (including export) is performed primarily by rail. As grain export grows rapidly and subject to the current technical condition of the railway, there is a shortage of special rolling stock - grain hoppers (which is most evident in the peak period of transportation from September to November). In this situation, the universal rolling stock has to be used for such transportation - covered cars, the rationalization of use which is the subject of the study in this article.

\section{Literature Review}

Currently, in Ukraine and other countries of the world, practical and theoretical issues of the transportation of vegetable cargo have been developed. In the study [1], the effectiveness of bimodal shipping of grain cargo in containers vs. other methods of their delivery to seaports was evaluated. The author obtained the dependence of the cost of delivery of grain cargo to the freight forwarder's seaports routes on the distance, taking into account the design features of the rolling stock and the specific functioning of the seaport stations.

There is a need for critical changes in the existing grain logistics system, which is proposed in the article [2] as the transition to a new system of concentration of export grain shipments on cluster cargo-forming nodes and routing transportation to seaports. The use of route trains will allow managing the entire cycle of transportation of grain cargo, controlling peak loads and seasonality of demand, solving the problem of rolling stock shortage and avoiding congestion on access roads to the port terminals.

Introduction of forwarding routing is also proposed in order to improve the transportation technologies of grain cargo, which requires the development of technical facilities of access roads of grain elevators [3]. The authors of the work [4] proposed transportation technologies of grain cargo within the regional grain cluster which are supposed to control routing of car shipments, redistribution of cargo transport stock between ports, taking into account the construction of a dry bulk cargo port, which provides for the capacity for transshipment of additional volumes of grain cargo. 
New generation cars should be produced to renew the freight car fleet and reduce the number of specialized cars (grain hoppers) with expired service life. Designing a new generation "dropletshaped" body in the car with a larger volume due to the maximum quality use of the design dimension is planned to solve this problem. In this case, the car has small linear dimensions, namely the length and the base, which can be considered as an advantage vs. competitive options. Due to the increased volume of the body, the load capacity and the short length of the car, the train of the same length may be made up of more such cars than of competitive cars, which will generally allow transporting more cargo [5].

The author of the article [6] has investigated the supply chain of food grain in India. The developed mixed integer nonlinear programming model will allow contribute to minimization of expenses for cargo operations, transportation, operational expenses for delivery of grain cargo from clusters of procuring production centers to the state consumer warehouses. The article [7] notes the need for reliable forecasting of volumes of goods transported by rail in conditions of rolling stock shortage. It has been determined that in the structure of the time series of volumes of transported grain and milling products, a definite seasonal component is observed, which affects the loading of rolling stock and transport infrastructure.

The article [8] presents conceptual and mathematical models of the internal supply chain of grain, which includes trucking, storage at the grain elevators and rail transportation. The results of the train-handling capacity model have showed that the transfer of grain from the conventional service to the shuttle service increases significantly the train-handling capacity of the railway.

The analysis of literary sources concerning the transportation of grain cargo has shown that numerous studies have been carried out, but no consideration is given to the choice of alternative rolling stock (covered car) for the transportation of grain cargo and their processing products.

\section{The Main Problems of Transportation of Grain Cargo by the Ukrainian Railway}

The main purpose of additional grain production is export, the share of which in the structure of grain transportation is $84.2 \%$. According to the State Fiscal Service of Ukraine, the export of grain crops in 2017 amounted to 41.827 MT (by $3.9 \%$ more than in 2016) for $\$ 6.501$ billion. Export of corn, wheat, and barley has traditionally provided the largest share of revenue among this commodity group.

The share of Ukraine in the global production of sunflower oil is about $34 \%$, and $57 \%$ in exports. The turnover of oil and fat products in 2017 exceeded $\$ 5.77$ billion vs. $\$ 5.07$ billion in 2016 (an increase of $13.9 \%$ ). Sunflower oil has the largest share in the structure of export of oil and fat products $78.0 \%$ (key consumers include India $-44.7 \%$, the EU $-24.2 \%$, China - 10\%) together with the sunflower oil meal $-14.6 \%$ (key consumers include the EU $-58.0 \%$, Belarus $-12.0 \%$, Turkey $-5.9 \%$ ).

In general, the export transportation is performed primarily by rail. Volumes of transportation of grain cargo increase by 7 to $15 \%$ annually (18.4\% in 2017), and such cargo already amounts to almost $11 \%$ in the total freight turnover of rail transport, and has prospects for further significant growth. The changes of transportation volumes of grain cargo by rail for 2014-2017 and the forecast for 2018 according to Ukrzaliznytsya PJSC are shown in Figure 1.

In this situation, the railway industry should concentrate on solving the priority issues related to the sharp increase in the volumes of grain transportation with the limited available resources and the need to retain, and if possible, expand this segment of the market. Therefore, the development of the railway transport system with the purpose of achievement of the necessary capacity for such transportation for the minimum logistic costs remains the urgent issue for the Ukrainian economy.

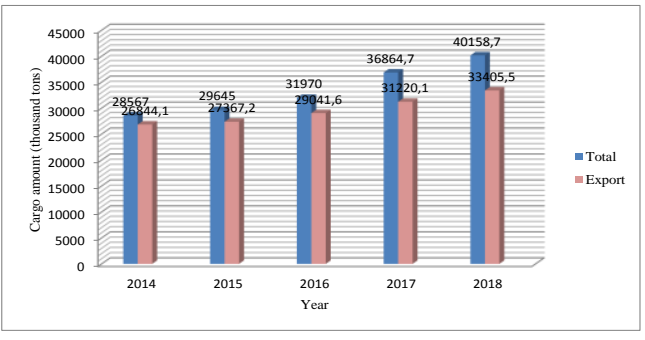

Fig. 1: Change of volumes of grain cargo transported by the Ukrainian railway in 2014-2017 and forecast for 2018

The need for transportation exceeds critically the capacity of the railway and the available rolling stock fleet. In 2017, the total number of grain hoppers capable of delivering grain to the port increased to 16.390 vs. 14.000 in 2016. The increase in the car fleet, however, failed to result in improving the situation with the export of grain. For example, about 2.000 grain hoppers are loaded with grain cargo every day, while the need is 2.500 to 3.000 cars. At present, the average age of Ukrainian grain hoppers is up to 26 years, the design service life being 30 years. Moreover, the service life of about $30 \%$ of grain hoppers has already expired (they are more than 30 years old), 62\% of cars are operated in their last service years (21-30 years), and only $8 \%$ grain hoppers were manufactured less than 10 years ago. That is, the wear and tear of grain hoppers is more than $92 \%$, which leads to their shortage in the peak periods of transportation.

The round trip of a grain hopper at Ukrzaliznytsya PJSC is 9.4 days, and that of the cars of the own fleet is almost 12.7 days. However, for normal exporting of $40 \mathrm{MT}$ of grain, the round trip of cars should not exceed 6 days.

The state of cargo safety at the Ukrainian railways of remains very unsatisfactory: since the traffic police units in the Ministry of Internal Affairs of Ukraine have been dismissed, the number of cases of offences against property has increased almost threefold. In 2017,5814 cases of theft were recorded. Total $\$ 2.1$ million worth material losses were incurred (total 4,111 cases were registered and about $\$ 1.4$ million worth of damages were inflicted in 2016). In 2017, the paramilitary security of Ukrzaliznytsya PJSC detained 1,156 intruders (vs. 850 in 2016).

Only complex measures taken during the transportation will allow reducing significantly the number of cases of non-safety of cargo. For this purpose, the stations should be further equipped with innovative technical means of control: intelligent sensors, mobile applications; continuous enhanced monitoring of movement and protection of freight trains with cargo that have the highest risk of theft should be establish and other effective measures in cooperation with the guards should be taken.

\subsection{Choosing an Alternative Rolling Stock for Trans- portation of Vegetable Cargo}

Some promising vegetable cargo (which are in demand in the EU countries), for example, oil meal, granulated sunflower hulls (fuel pellets) can be transported also in universal - covered - cars.

In the general purpose covered cars, the cargo is transported in bulk with the use of door enclosures. The standard door enclosure type for transportation of grain cargo in covered cars is wooden door panels. In accordance with the current Technical Conditions for Cargo Loading and Securing [9], the cargo should be loaded in a doorway space $100 \mathrm{~mm}$ below the upper edge of the panel (the maximum height of the panel from the floor of the car is $2,170 \mathrm{~mm}$ ). An increase in the height of the load of grain towards the end walls of the car is allowed at a distance of not less than $1,500 \mathrm{~mm}$ from the edge of the panel.

Model 11-280 car has been selected as the basic one for conducting a study on the placement of grain cargo in the covered car. The loading scheme for a universal covered car with vegetable 
cargo using wooden enclosure panels is shown in Figure 2. The maximum loading capacity of a car with consideration of different bulk density of vegetable cargo has been studied and the low degree of use of load capacity and loading volume within the range of low loading density of cargo has been established. Therefore, a new enclosure should be developed which would allow the most efficient use of the capacity of the car.

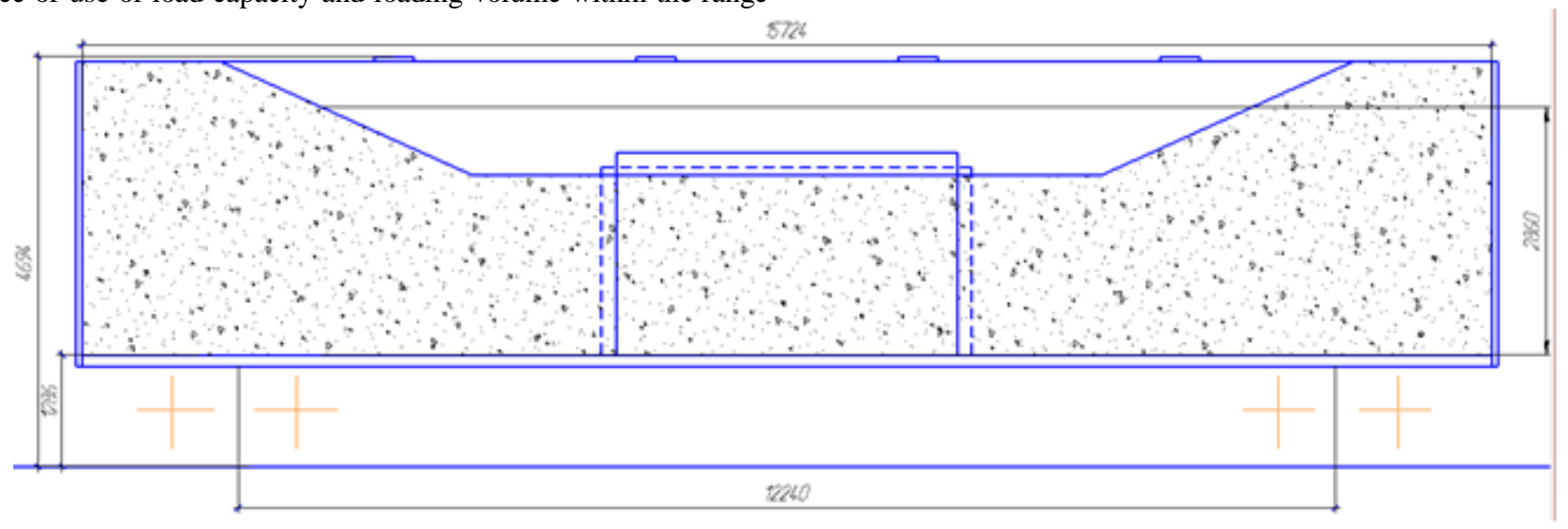

Fig. 2: Scheme of loading of the 11-280 universal covered car with vegetable cargo using wooden door panels

It is proposed to enclose the doors of the car with reusable devices - metal door panels, which allow to load the car in doorway space without restrictions on the loading height and to ensure full safety of cargo with the increased use of loading capacity of cars. At the same time, the Technical Conditions for Cargo Loading and Securing should be updated (in particular, Chapter 11 "Placing and securing cargo in covered cars") (Appendix 3 to Agreement on International Goods Transport by Rail (SMGS)), primarily, regarding the upgrade of the main models of covered universal cars, the commissioning of multi-purpose vehicles that would allow full overlapping the doorway space and have adequate protection against possible loss of cargo during the carriage.

SchDM-1 metal door panels (hereinafter referred to as panels) are removable multi-purpose means designed to prevent the spillage of bulk cargo (in particular, sunflower seeds and its processing products with the size of fractions from 4 to $50 \mathrm{~mm}$ ) when they are transported in the universal covered railway cars. The design of the panels allows them to be mounted (disassembled) manually using electric hand tools; bulk cargo can be unloaded through holes (hatch) in each panel section into the charging hoppers, followed by opening panel sections for use of electric bucket loader; ensures the reliability of fastening of removable parts to prevent their involuntary loosening and loss during operation; prevents threaded connections from self-unscrewing; convenient and easy access to structural elements that need replacing during operation; prevents vandalism; can be operated at ambient temperatures from -45 to $+40^{\circ} \mathrm{C}$. Panels sections can be opened with effort no more than $70 \mathrm{~N}$. The average mean time between failure is not less than 10,000 hours, and the full average life time is at least 5 years. The frame of the developed panel (Figure 3) consists of horizontal and vertical tubes with a square cross section $60 \times 30 \times 2 \mathrm{~mm}$. Three mounting brackets with a $\emptyset 10 \mathrm{~mm}$ bolt hole for securing to the car through the technological holes in the car near the door pots are welded to the outer vertical tubes. The frame is attached to the car from the inside of the car in the doorway space and is squeezed tightly to the wall of the car with bolted connections. Four panel sections with dimensions of $2230 \times 947.5 \mathrm{~mm}$ each are mounted in the panel frame and fixed to the inner vertical tubes of the square cross-section of the frame with three loops consisting of two collars, each pair of which is connected with a removable axial pin. Similarly, the panel sections are fixed to each other (the first one with the second one, and the fourth one with the third one). There are upper and lower latches passing through the two collars to fix each panel section, with falling stoppers $400 \mathrm{~mm}$ long and a $100 \mathrm{~mm}$ long handle retracted perpendicular from a $\emptyset 18 \mathrm{~mm}$ circle. The panel frame and partition sections are made of horizontal and vertical tubes with a square section of $60 \times 30 \times 2$ $\mathrm{mm}$, the tubes are welded. Inside of the car, the surface of each panel section is covered with a $1.5 \mathrm{~mm}$ thick metal sheet, welded to the frame and partitions of the panel section. At the same time, the metal sheets between the panel frame and the panel sections overrides the dimensions of the panel section by $15 \mathrm{~mm}$, thus forming door strips to cover the gaps between the panel sections in order to prevent the spillage of small fractions (to improve the safety of transport).

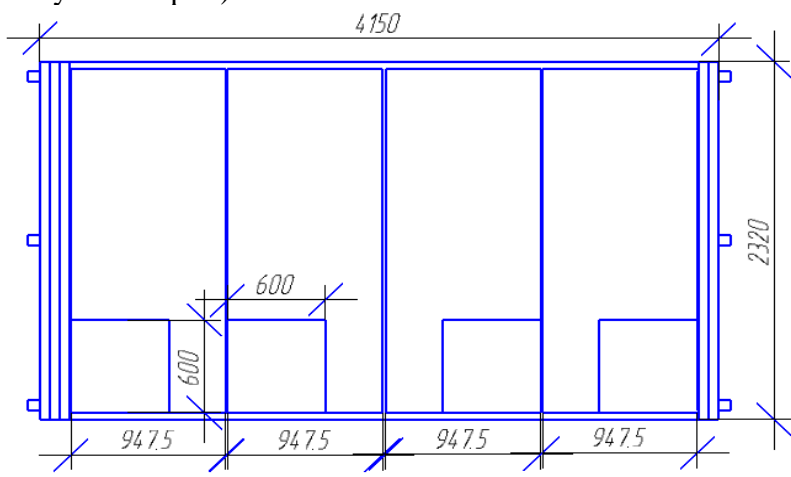

Fig. 3: Scheme of the SchDM-1 metal reusable door panel for the 11-280 covered car

In the lower part of each panel section, hatches made of $2.0 \mathrm{~mm}$ thick metal sheet with a size of $600 \times 600 \mathrm{~mm}$ are made for the cargo unloading in the doorway space by gravity for the subsequent section by section opening of the inter-door panel for using mechanization means (electric bucket loaders). The hatch flapper guides are made of a $25 \times 25$ angle. There is a handle on the hatch flapper for moving it along the guides and stoppers that prevent from full removal of the flapper.

The opening between the panel frame and the car in the upper part of the doorway is closed with a $2.0 \mathrm{~mm}$ thick metal sheet using mechanically fastening to the upper horizontal tube of the square panel frame, forming a "canopy" preventing the leakage of small fractions in the upper part of the doorway. In the operating state of the reusable metal door panel, all clearances between the panel sections, between the panel frame and the panel sections, between the panel frame and the elements of the inner side of the car are overlapped with door strips and the "canopy", thus providing a complete guarantee of the safety of the cargo in the car during transportation.

The overall dimensions of the reusable metal door panel without mounting brackets and canopy are 4,150 x 2,320 x $60 \mathrm{~mm}$; with the mounting brackets and the canopy $-4,290 \times 2,370 \times 60 \mathrm{~mm}$, total weight is $322.5 \mathrm{~kg}$. The completet set for a car includes 2 panels with a total weight of $322.5 \times 2=645.0 \mathrm{~kg}$.

Before loading, the reusable metal door panels are put into operating condition: the panel sections are set to the closed position and fixed with upper and lower larches, the hatch flapper is placed in the lowest position (to the stopper on the flapper). 
After unloading of the cargo from the car before the departure of the empty car, the reusable metal door panels are also put into operating condition: panel sections are set to the closed position and fixed with upper and lower larches, the hatch flapper is placed in the lowest position (to the stopper on the flapper), i.e. the reusable device means is not removed from the doorway.

Studies have been conducted for the load of sunflower meal. This product is obtained after pressing the vegetable oil on presses of different design from the treated sunflower seeds. It consists of crushed remnants of sunflower kernels. This product contains about $30 \%$ proteins and up to $7 \%$ fat. The weight fraction of moisture and volatile substances is 7 to $11 \%$, the weight fraction of fat and extraction substances is not more than $1.5 \%$. It is a hazardous cargo of Class 4.2 "Self-heating substances". It is allowed to be shipped in bulk in covered metal cars. The temperature of the meal during loading in winter should not exceed $35^{\circ} \mathrm{C}$, while in the summer it should not exceed the ambient temperature by more than $5^{\circ} \mathrm{C}$.

The sunflower meal is made in the form of granules, grains or pressed plates. It is used as a concentrated fodder for farm animals with high protein content; or as a component of mixed fodders. The bulk density of the meal to be transported should be from 450 to $670 \mathrm{~kg} / \mathrm{m}^{3}$.

The developed loading scheme for a universal covered car with vegetable cargo (sunflower meal) using of a metal door panel is shown in Figure 4. The cargo is loaded into the car evenly on the entire floor area of the car to the loading height, which is possible when the car is loaded through the upper loading hatches, and such hatches should not be fastened from inside the car.

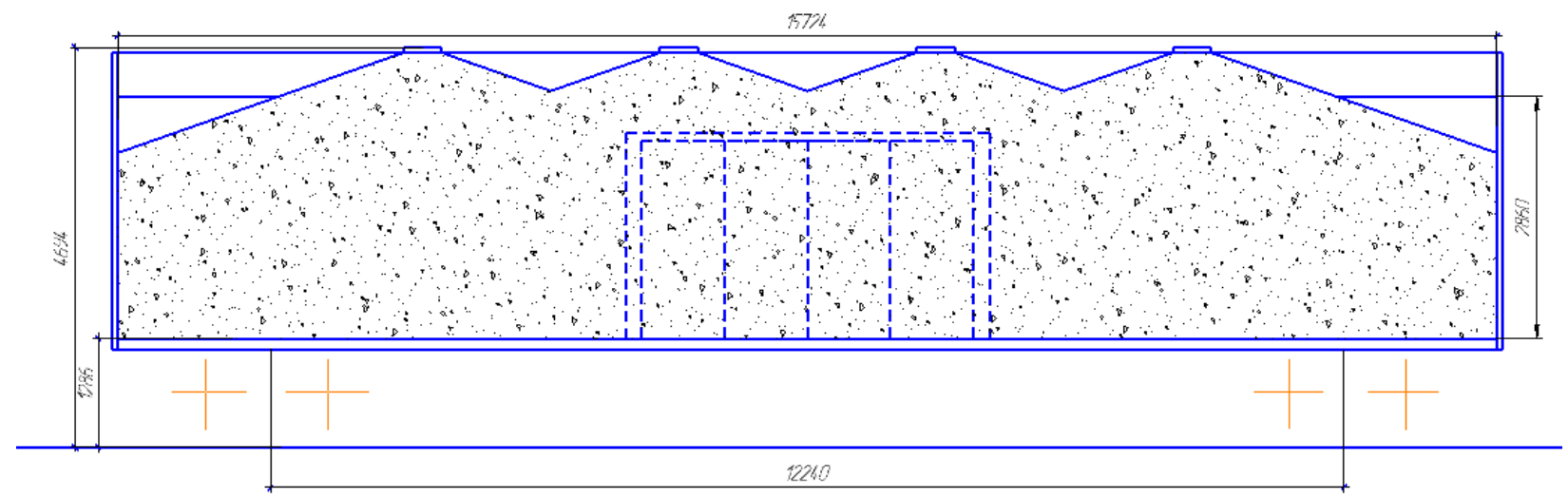

Fig. 4: Scheme of loading of 11-280 universal covered car with vegetable cargo using a metal door panel

The sunflower meal loaded into the car has a wide loading density range which results in the varying weight of the loaded cargo in the car. According to the conducted studies, is the load density is $540 \mathrm{~kg} / \mathrm{m}^{3}$ and more, the freight weight in the 11-280 car using metal door panels is constant and is $67.3 \mathrm{t}$. The dependence of the loading of the car on the load density using two types of enclosure of the doorway space is shown in Figure 5.

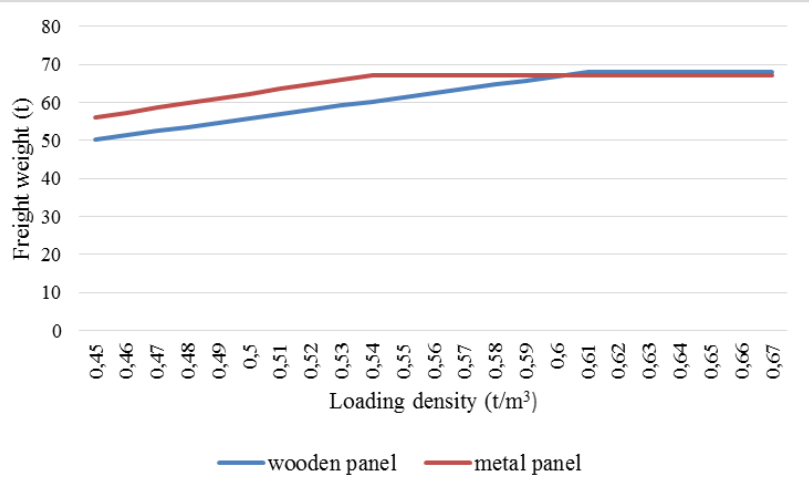

Fig. 5: Dependence of loading of the 11-280 car from cargo density (meal) using two types of enclosure of the doorway space (wooden and metal panels)

When metal door panels are used and the cargo density is up to $540 \mathrm{~kg} / \mathrm{m}^{3}$, the maximum loading volume of the car can be utilized, taking into account the bulk loading through the upper loading hatch. If a cargo density is more than $540 \mathrm{~kg} / \mathrm{m}^{3}$ and the full load capacity of the car is used, the loading volume of the car is not fully used. When wooden door panels are used with a cargo density of up to $610 \mathrm{~kg} / \mathrm{m}^{3}$, the complete loading volume of the car can be used, however, in this case the used loading volume of the car will be noticeably lower than when using metal door panels. If a cargo density is more than $610 \mathrm{~kg} / \mathrm{m}^{3}$ and the full load capacity of the car is used, the loading volume of the car is not fully used.

\subsection{Determination of the Economy of Covered Car Fleet Using Metal Door Panels}

The efficiency of the proposed measures to reduce the additional operating fleet of universal covered cars for transporting vegetable cargo is determined taking into account the following.

The operating fleet of cars is determined from the ratio:

$n_{o p}=\frac{\sum Q l_{l}\left(1+\alpha_{e n}\right)}{S_{c} P_{s l} l_{d} \beta_{o p}}$,

where $\sum Q$ is the cargo turnover, $\mathrm{t}, l_{l}$ is the kilometrage of the loaded car per round trip, $\mathrm{km}, \alpha_{e m}$ is the empty run ratio, $S_{c}$ is the average daily kilometrage of the car, $\mathrm{km}, P_{s t}$ is the static load (loading) of the car, $\mathrm{t} / \mathrm{car}, l_{d}$ is the transportation distance, $\mathrm{km}$, $\beta_{o p}$ is the ratio of operating ton- $\mathrm{km}$ net to tariff ton- $\mathrm{km}$.

Loading of a car using wooden door enclosure panels is determined by the formula:

$$
P_{s t}^{w}=V_{l}^{w} \rho_{c} \leq P_{c}^{\prime},
$$

where $V_{l}^{w}$ is the loaded volume of the car using wooden enclosure door panels with the relevant cargo density, $\mathrm{m}^{3}, \rho_{c}$ is the loading density of cargo, $\mathrm{t} / \mathrm{m}^{3}, P_{c}^{\prime}$ is the loading capacity of a car excl. the weight of wooden panels, $t$.

Loading of a car using proposed metal enclosure door panels:

$P_{s t}^{m}=V_{l}^{m} \rho_{c} \leq P_{c}^{\prime \prime}$,

where $V_{l}^{m}$ is the loading volume of the car with the use of proposed metal enclosure door panels with the relevant cargo density, 
$\mathrm{m}^{3}, P_{c}^{\prime \prime}$ is the loading capacity of a car excl. the weight of the metal enclosure door panels, t.

Change of the operating fleet (in unit fractions) after the introduction of the proposal (use of metal enclosure door panels) under other things equal will be:

$$
\Delta n_{o p}=\frac{n_{o p}^{m}}{n_{o p}^{w}}-1,
$$

where $n_{o p}^{m}$ is the operating fleet when metal enclosure door panels are used, cars, $n_{o p}^{w}$ is the operating fleet when wooden enclosure door panels are used, cars.

After transformations taking into account the formulas (1) - (3), we obtain

$$
\Delta n_{o p}=\frac{V_{o p}^{w}}{V_{o p}^{m}}-1
$$

The general representation of the obtained results of changing the operating car fleet when use of loading capacity of a 11-280 car is changed within the range of loading density of sunflower meal is shown in Figure 6.

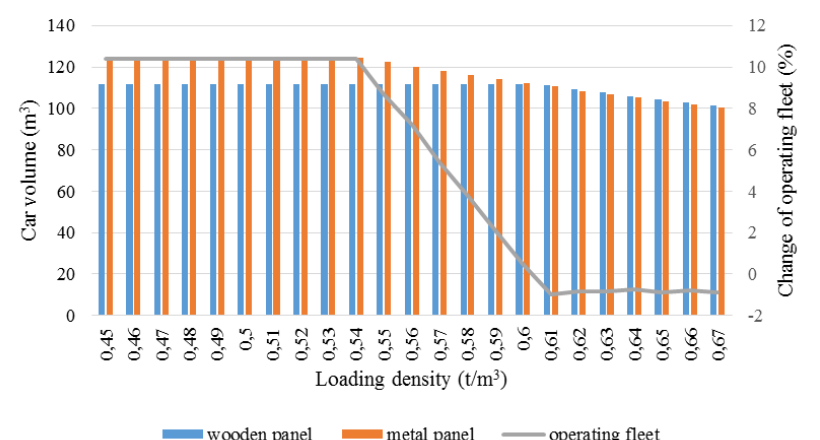

Fig. 6: Dependence of the operating fleet of universal covered cars on loading density of sunflower meal using various means of door panels

\section{Conclusion}

With the significant increase in grain production in Ukraine, certain difficulties occur in their transportation by rail due to the level of development of the transport industry (due to the shortage of specialized grain hoppers in the peak period of transportation). The forced use of alternative railway rolling stock (covered cars) for transportation of vegetable cargo requires the improvement of the transportation technology, especially when performing initial and final operations (including loading, door space enclosure, cargo safety during the transportation, and unloading).

The current technology used with covered cars for the transportation of vegetable cargo does not fully comply with the modern requirements, especially concerning doorway closing. The definitive height of wooden door panels $(2,170 \mathrm{~mm})$ and the requirements of normative documents regarding loading parameters at the same time leads to underutilization of the loading volume of the car in the doorway space and, as a result, to underutilization of the loading capacity of the covered car.

The use of metal door panels has been proposed, which allow to load the car in a doorway space without restrictions on the loading height and to provide full safety of the cargo with increased use of the load capacity of covered cars. However, the efficiency of using such panels depends essentially on the loading density of the cargo. The conducted studies have shown that the most reasonable use of the proposed panels is then loading density is up to $540 \mathrm{~kg} / \mathrm{m}^{3}$. The utilization of the loading volume of the car is increased by about $13 \mathrm{~m}^{3}$, and the utilization of the loading capacity of the car (for the load of sunflower meal) is increased by 5.8 to 7.0 tons vs. those when wooden door panels are used.

In the range of cargo density from 540 to $610 \mathrm{~kg} / \mathrm{m}^{3}$, the efficiency of the use of the proposed panels gradually decreases, which is associated with the achievement of the full utilization of the carrying capacity of cars (when wooden door panels are used, full use of loading capacity is achieved if loading density is more than 610 $\left.\mathrm{kg} / \mathrm{m}^{3}\right)$.

If the cargo density is more than $610 \mathrm{~kg} / \mathrm{m}^{3}$, both options of the doorway enclosure become practically equal.

The study of the economy of the covered park car fleets when vegetable cargo are transported (due to the increase in the use of loading capacity of cars) when using door-metal panels suggest three categories of economy (example of a 11-280 covered car):

- loading density of cargo up to $540 \mathrm{~kg} / \mathrm{m}^{3}$ - maximal economy of the car fleet of $10.4 \%$ is achieved;

- loading density of the cargo from 540 to $610 \mathrm{~kg} / \mathrm{m}^{3}$ - economy of the car fleet gradually diminishes;

- loading density of the cargo is more than $610 \mathrm{~kg} / \mathrm{m}^{3}$ - there is no economy on the car fleet.

In addition, it should be noted that the forced use of covered cars for the transportation of vegetable cargo is more suitable for small consumers that may not always have receiving hoppers at their unloading terminals for unloading grain hoppers. The possibility of unloading covered cars using bucket electric loaders, which are widely used in cargo handling operations, allows using covered cars with metal door panels for small consumers of rail transport services even if there is no shortage of grain hoppers. In addition, such an approach to maintaining the segment of small consumers of rail services is in line with the development of bimodal transport [10].

Thus, the study has established the possibility and efficiency of the use of alternative railway rolling stock (covered universal cars) with the proposed doorway enclosure (door panels) to ensure guaranteed cargo safety in the condition of shortage of grain hoppers and the efficiency level of use was determined, taking into account loading density of cargo.

\section{Acknowledgements}

We would like to express our gratitude to the organizers of the international scientific and technical conference "Technologies and Infrastructure of Transport" (Ukraine, Kharkiv, UkrSURT, 2018) for the possibility of validation of some materials of the study.

\section{References}

[1] Myamlin S.V., Korobyeva R.G., Malashkin V.V., Besarab D.A., Improving grain logistics through the introduction of bimodal technologies, Collection of scientific works of Acad. V. Lazaryan DNURT, 14 (2017), 69-77.

[2] Delz S.V., Logistic approaches to the evaluation of the efficiency of logistics schemes for export grain delivery, Logistics, 8 (61) (2011), 44-46.

[3] Kozachenko D.M., Bobrovsky V.I., Ochkasov O.B., Shepotenko A.P., Improvement of the technical equipment of access roads of grain elevators for loading of forwarding routes, Collection of scientific works of Acad. V. Lazaryan DNURT, 14 (2017), 50-60.

[4] Zubkov V.N., Mamaev E.A., Chislov O.N., Ivanchenko V.N., Ryazanova E.V., Chebotareva E.A., Perspective technologies of agricultural cargo transportation in the railway and sea communications, KubSAU Scientific Journal, 124 (10) (2016), 1-23.

[5] Fomin O.V., Murashova N.G., Voropay V.S., Kovalenko V.V., Present state of constructive perfection of bunker cars for transportation of grain and prospects for its development, Bulletin of the Azov State Technical University, 34 (2017), 192-201.

[6] Mogale D.G., Kumar Sri Krishna, Tiwari Manoj Kumar, Two Stage Indian Food Grain Supply Chain Network TransportationAllocation Model, IFAC-Papers On Line Vol. 49, No. 12 (2016), 1767-1772. 
[7] Butko T., Prodashchuk S., Bogomazova G., Shelekhan G., Prodashchuk M., Purii R., Improvement of technology for management of freight rolling stock on railway transport, Eastern European Journal of Enterprise Technologies 3/3 (87) (2017), 4-11.

[8] Hyland M.F., Mahmassani H.S., Mjahed L.B., Analytical models of rail transportation service in the grain supply chain: Deconstructing the operational and economic advantages of shuttle train service, Transportation Research Part E: Logistics and Transportation Review 93 (2016), 294-315.

[9] Technical conditions for cargo placing and securing. Annex 3 to the SMGS as of July 2017. http://www.uz.gov.ua/cargo_transportation/legal_documents/smgs/ dod3_01072017 / Accessed January 23, 2018.

[10] Lavrukhin O., Zapara V., Zapara Y., Shapatina O., Bogomazova G., Investigation into bimodal transportation process by modelling rail module states, Transport problems 12(2) 2017, 99-112. 